\title{
THE CANADIAN CONTRIBUTION \\ TO THE ANAESTHESIA TRAINING PROGRAMME OF THE WORLD FEDERATION OF SOCIETIES OF ANAESTHESIOLOGISTS*
}

\author{
R. A. GoRdon, M.D., F.R.C.P.(c), F.F.A.R.C.S.
}

THE STATED OBJEctrve and reason for being of the W.F.S.A. is "to provide better anaesthesia for all the peoples of the world." Although the Federation was formed in 1955, and although there was some discussion of training centres at the World Congress in Toronto in 1960, it was not until the meeting in São Paulo in 1964 that any concrete action was taken by the Federation to become actually involved in the promotion of training in anaesthesia at the international level. The stimulus on that occasion came from Dr. Robert Hingson of Cleveland, and I wish to take this opportunity to pay tribute to his enthusiasm and active involvement in forwarding this project.

At the São Paulo meeting an "Educational Foundation" was formed to proceed with plans for training centres in those parts of the world where trained anaesthetists are rare and modern anaesthesia is practically non-existent. Dr. Hingson was appointed chairman of the Foundation Committee, with two "continental trustees" from each continent or region, and with the President and Secretary of the Federation acting ex officio.

It was evident from the first meeting of the trustees that there was a sharp difference of opinion as to the optimum method of achieving our aims. Dr. Hingson's concept was that we should establish "Continental Training Centres" with considerable budgets and equipment, to which trainees would be sent by their governments for various periods of training. These would be staffed by a basic indigenous staff, reinforced by "visiting professors" from abroad, who would volunteer their services for short periods of time. Transportation and expenses were to be paid by the World Federation Foundation and the government of the host country. You are all aware that such a centre has now been established in Caracas, Venezuela, for the continent of South America.

Among the trustees there are those of us who believe that this approach to the dissemination of training is wrong in principle, and who have opposed its extension to other continents. I am glad to have this opportunity to put the alternative point of view to you, as a representative body of Canadian anaesthetists, and to tell you of decisions which were taken by the Executive Committee of the World Federation in Copenhagen last summer, and how they may affect the Canadian contribution to this effort.

If we are to extend the availability of modern anaesthesia to the under-doctored areas of the world, we must realize that our primary objective must be to teach every physician something about anaesthesia-in fact, enough that he may be able to manage the ordinary anaesthetics required in the environment in which he

"An address to the Council, Canadian Anaesthetists' Society, February 1967.

Can. Anaes. Soc. J., vol. 14, no. 6, November, 1967 
works. The requirements of his environment and the limitations it imposes on drugs and equipment will of necessity dictate what his basic training should be. There can be no doubt that the best time and place to do this will be in the medical schools of the developing countries during the undergraduate and intern years. To achieve this requires the establishment and maintenance of strong teaching departments of anaesthesia in these medical schools, which must eventually be staffed by appropriately trained indigenous physicians. It is to be noted that, almost without exception, the medical schools of Africa, Asia, and South America have such departments. To fulfil their teaching functions, however, most need strengthening by the addition of further well-trained anaesthetists. The teaching staffs of such departments should be "indigenous" at the earliest possible moment, and in most instances this means the recruitment and training of the appropriate native physicians.

It has been my thesis that the designation of any one department of anaesthesia as a "Continental Training Centre" would delay, if it did not entirely destroy, the development of adequate teaching departments in all the other medical schools of a region. A partial training in anaesthesia would be granted to a small number of physicians at the cost of depriving the whole region of the facilities required to give useful training to every medical student and intern.

At the meeting of the Trustees of the Educational Foundation with the Executive Committee of the W.F.S.A. in Copenhagen, it was agreed that this point of view would govern the development of teaching centres for anaesthesia in Africa, and that its possibilities should be explored in Asia before any further consideration would be given to the establishment there of a "continental" centre. The programmes of development currently being undertaken by the Canadians and British in Nigeria, Uganda, and Kenya were recognized, and it was further recognized that, as far as the World Federation was concerned, development in Nigeria would be considered a Canadian responsibility. This may be a very tall order indeed, and the present tribal schisms in Nigeria are resulting in problems which could not be foreseen when Canadians first became involved in this project five years ago.

It may seem strange to some people in view of our acknowledged shortage of anaesthetists in Canada and elsewhere in the western world, that the World Federation should be advocating that we send teachers of anaesthesia to developing countries. But we must admit that "shortages" are relative, and I am one of those who believe that we must exert ourselves to give these peoples the really very meagre help which they ask of us.

Having said this, I admit that from the practical point of view our resources to carry out such projects are limited. I have, therefore, personally advocated and shall continue to advocate what appears to be a uniquely Canadian attitude in our undertakings. I am anxious to explain this attitude because it has been widely misunderstood both at home and abroad. If we are to leave behind us in the developing countries anything of lasting value, we must take on relatively small projects, which are possible with our limited resources of manpower and money, and we must see them through to a successful conclusion. This statement is trite in the extreme, but its importance for the ultimate good which we may 
accomplish and for the Canadian image abroad cannot be overemphasized. In practical terms, and using the Nigerian situation as an example, it means that we will be quite unable to do at one time all the things which may be asked of us.

To the present time there have been two medical schools in Nigeria. The school at Ibadan was established in 1952 as a dependency of the University of London, and remained as such until 1963. This was its position, then, in 1962, when the Department of Anaesthesia of the University of Toronto undertook the administrative problems of establishing an autonomous department of anaesthesia in the new University of Lagos Medical School. I must say, immediately, that we found very quickly that we could not carry this through with our own resources, and I wish to pay the greatest tribute to the people from Queen's University (Dr. Earl Russell and Dr. Dick McCutcheon), to Dr. Eric Webb of the University of British Columbia, and to Dr. Joe McCammon from Manitoba, to say nothing of their wives and families, for their outstanding contributions to the project. It has, however, required all the resources which could be mustered to carry forward this undertaking.

The danger now presented to us, one which must be avoided even at the risk of appearing callous, is the pressure to disperse our resources and to give "a little help" to more people-i.e., to more medical schools. This pressure commenced in 1964, shortly after the withdrawal of the University of London from Ibadan. But as I have already suggested, we must bite off only what we can chew, chew it thoroughly, and digest it before we take the next bite. The attitude which I have taken personally to every approach which has been made to me to recruit Canadian anaesthetists for Ibadan and, later, Accra, has been that at present this could be done only after the commitments at Lagos had been met. On this basis Dr. Ronald Lambie of Winnipeg spent one year at Ibadan from January 1965 and at the present time Dr. Morris Beckham of Kitchener is head of the department there. Fortunately, these Canadians have managed to change the department at Ibadan from a purely hospital service organization under the Department of Surgery to an autonomous department with teaching potential, although at present with limited resources to carry out this teaching. It is gratifying to know that, due to the example set by our compatriots and colleagues in Lagos, not only Ibadan but new medical schools presently or shortly to be established elsewhere seem to think of Canada as the source of departments of anaesthesia. I believe that we are not at present able to supply them because we have not yet completed our first obligation. It is evident to me that our resources at present do not permit additional obligations without fatal dilution of the results.

In undertaking such projects, certain principles must be established and adhered to in good faith by both parties. The first of these is agreement that the aim is to establish a modern teaching department in the medical school, appropriate to the curriculum and the medical environment of the region, and to maintain it until it can ultimately be staffed by well-qualified and energetic native teachers. The second principle is agreement that the teachers provided from abroad are to teach, not primarily to provide hospital service. This not only means that they will teach students, but implies an obligation on the part of the host 
institution or the host government to recruit trainees in the specialty, and trainees of a calibre which will make possible the development of an indigenous teaching staff who will carry on when the day for weaning arrives. The final principle is that the host institution should be under an obligation to continue support of the department after our people have withdrawn.

As a matter of interest to you I think I may, for the first time, publicly recount some points in the history of the University of Lagos project which has resulted in decision of the W.F.S.A. that "the Canadians will be responsible for Nigeria." It all began when the Minister of Health of Nigeria and the Dean-elect of the proposed school visited the Faculty of Medicine of the University of Toronto in February of 1962 to ask our help in establishing a new medical school in Lagos. Among other things the Dean asked specifically for help in anaesthesia. I undertook to put the proposition to our staff, and Dr. Shirley Fleming volunteered to go to Lagos as our "first shift." Dr. Fleming was appointed Professor of Anaesthesia at Lagos, and arrived there in July 1962. At that time the only people on the staff were the Dean and herself. She was joined a short time thereafter by Dr. Earl Russell of Kingston and later by Dr. Aileen Adamson of Cambridge and Dr. Oswald Dawkins from Jamaica and the University of Michigan. The only teaching they could do consisted of giving a few lectures to the new students about the importance of anatomy to the anaesthetist. During this year the salaries of the Canadians were paid (at North American rates!) by the University of Lagos. By the spring of 1963 it became evident that continuation of these salaries from that source was impossible for both economic and political reasons, and Dean Hamilton of the Faculty of Medicine at the University of Toronto proposed to the Department of External Aid that the Canadian government should take over this responsibility. The Department at first displayed a firm resolve not to undertake this commitment, but that decision was reversed in the summer of 1963, and Dr. Fleming and Dr. Russell returned to Lagos that autumn with Canadian government support, accompanied by Dr. Bob Hooper, a senior resident from the University of Toronto course.

By the end of 1963, however, frustrations, including the reluctance of Nigerians to appear for training in anaesthesia, had reached the point where our staff had determined to retire from the scene and return home by Easter. In January of 1964 my Dean sent me off to Lagos to look into these problems and I must confess that I thought I was going there to organize a retreat. In the event, however, we were able to arrive at certain agreements and to lay down principles which provided a more encouraging outlook, and we are now able to report that the first class of students is about to graduate, with enough training and skill in anaesthesia to enable them to manage a large proportion of the problems which they are likely to meet in a country practice, and that postgraduate trainees of the department now occupy the four "house" appointments. The Nigerian Associate Professor is presently in Toronto for six months where he is involved not only in our teaching activities and special units, but in studying a number of facets of faculty administration. We also have in our training programme at Toronto a University of Ibadan graduate who had his first year of training at Benin and Lagos under the tutelage of our Canadians, and who will return as consultant 
anaesthetist at the teaching hospital to be built at Benin in the Mid-West Region. We have now reached the stage where "weaning" of this department should be possible over the next three or four years, with every prospect of leaving behind a staff of competent teachers of anaesthesia who will multiply themselves in geometric progression to provide better anaesthesia for all the people of Nigeria. I am sure that all who have been involved and who have devoted part of their life and energies to this project will be proud of the result, and personally I have considered myself most fortunate to have had an opportunity to be involved in it even in a small way.

Before I conclude I think I should say something about the question of the standards of training which we should achieve in the medical schools of developing countries, and who should be the beneficiaries of the teaching which we provide for them. This requires consideration of local pride and opinion, as well as of the long-term results of programmes which we may initiate.

Although medical schools are established to provide physicians for the community and not for the academic gratification of medical scientists, and although the pressure to provide large numbers of doctors quickly is particularly strong in underdeveloped regions, no one-whether he be physician, politician, military dictator, civil servant, or the man in the street-will willingly accept a second- or third-rate medical school. I do not think any of us here would willingly be associated with the development or perpetuation of a second- or third-rate school. If we are honest men, then, we will co-operate with our friends in the underdeveloped countries to develop schools of which we ourselves would be proud. However, in doing this, we must recognize that in a developing economy, where the generation of capital lags far behind the social demand, the provision of lavish equipment or the lavish provision of equipment and personnel may be quite impossible. This is no excuse for settling for the second rate, but it simply means that impatience must be curbed to accept the fact that accomplishment of some objectives must wait till next year. 